\title{
Arbor
}

\section{La Junta de Pensiones de Ingenieros y Obreros en el Extranjero 1907-1936}

\section{Francisco Villacorta Baños}

Arbor CLXX, 669 (Septiembre 2001), 127-146 pp.

\section{Introducción}

Los estrechos vínculos existentes entre formación y sistema productivo apenas necesitan hoy en día ser ponderados. Desde siempre, pero particularmente desde que la organización industrial comenzó a desplazar su centro de gravedad desde la experimentación empírica hacia el uso sistemático de la ciencia y a adentrarse en el apasionante campo de la organización científica del trabajo, entre ambos territorios comenzó a generarse una activa corriente de intercomunicación e intercambio en la que, podemos decir metafóricamente, capital económico, capital científico y capital humano han intercambiado con notable provecho sus respectivos patrimonios accionariales. En su estrecha interconexión se asienta, en definitiva, el fundamento de las políticas educativas e industriales de todos los Estados modernos. En cuanto tal constituye un insoslayable punto de partida que conviene emplazar en el frontispicio de este estudio, cuyo tema, como veremos, se relaciona estrechamente con la cuestión, aunque el carácter monográfico con que está planteado impida el tipo de prospección particular en ella que merecería a tenor de su importancia.

Ese mencionado tema concreto versa sobre las iniciativas emprendidas desde comienzos del siglo XX con el objetivo de establecer pensiones en el extranjero para profesores, estudiantes y obreros con el fin de permitirles ampliar o perfeccionar sus respectivos ámbitos de competencias en contacto con instituciones educativas, centros industriales 
o explotaciones agrarias de punta de los países europeos más avanzados. Estas iniciativas cristalizaron definitivamente a partir de 1907 en pensioneés de ampliación de estudios para ingenieros y de formación en nuevas técnicas y procedimientos empíricos para obreros manuales empleados en fábricas, talleres o granjas españoles, confiadas a un organismo estatal autónomo, la Junta de Pensiones de Ingenieros y Obreros en el Extranjero, que a partir de entonces desarrollará su obra ininterrumpidamente hasta 1936. Por comparación, se impone inevitablemente la referencia a la otra Junta, la Junta por antonomasia, la de Ampliación de Estudios e Investigaciones Científicas, cuya importancia resulta superfluo resaltar aquí. Pero mientras que conocemos ésta ya medianamente bien, la primera, en cambio, no ha merecido hasta este momento ningún tipo de referencia, a pesar de tratarse, como se trata, de una iniciativa paralela por su cronología, su carácter y sus funciones a la de Ampliación de Estudios, y merecedora como ésta de una detallada reseña. Lo avalan así tanto la importancia de sus realizaciones concretas como sus significados en el marco de un contexto socioeducativo de amplio radio, que incluye el de la formación técnico-profesional de la mano de obra obrera, una cuestión, dicho sea de paso, bastante olvidada de la historiografía actual ${ }^{1}$.

En lo dicho se concentra el enunciado puramente empírico de la labor encomendada a la Junta de Pensiones. No es en sí misma una labor desdeñable. En teoría, el intercambio científico, la transmisión de experiencias de organización empresarial, la formación en nuevas técnicas industriales han constituido un importante valor añadido en el desarrollo de la ciencia y la industria modernas. En la práctica, según veremos, la Junta cumplió su tarea con eficacia y dió origen a destacadas iniciativas de formación y documentación profesional. Pero a partir de ese somero recuento de objetivos y realizaciones es posible también, además, desplegar un rico contexto de condicionantes y significaciones, en los que esa simple labor adquiere lugar propio en un marco de análisis más amplio y cronológicamente muy significativo. Así lo queremos reflejar en la estructura del trabajo, al resaltar autónomamente los dos contextos, de índole bastante diversa, en que las tareas de la Junta de Pensiones se inscribieron.

En el marco de partida, la entidad vino emplazarse en la bocana de una época por donde vino a canalizarse el aluvión de inquietudes del regeneracionismo de final de siglo, entre ellas la de la reforma pedagógica y la de apertura hacia Europa. Lo hizo en la parte correspondiente a la enseñanza técnica y la formación profesional, un sector que, todavía en mayor grado que el de la enseñanza superior 
clásica y de la educación primaria, vivía en una situación de lamentable esclerosis. Y lo hizo con todas las características de improvisación y ensayo, de elitismo y utopía, que alentaban en la mayoría de las iniciativas de renovación pedagógica de la época, caracterización genérica de las empresas del institucionismo, en cuya órbita se inscribe también ésta sin ningún género de dudas. Pero de la misma manera que sucedió en la Junta para Ampliación de Estudios, la ulterior confrontación de objetivos y logros, en el marco de una práctica institucional de intervencionismo estatal, le dio la decantación definitiva de las realizaciones útiles y duraderas, aunque ya dentro de un nuevo contexto, el que a partir de 1924 abre el nuevo Estatuto de Enseñanza Industrial del Directorio.

No se puede decir que este definitivo marco de ensamblaje de la Junta de Pensiones fuese menos utópico si se tiene en cuenta la desproporción entre sus ambiciosos objetivos y los precarios medios disponibles, pero al menos, por lo que respecta a la institución que nos ocupa, acertó a encontrarle un espacio propio dentro de un plan sistemático de desarrollo de la formación técnica, que comprendía desde la fase de pre-aprendizaje empírico hasta los grados superiores de la enseñanza técnico-profesional. El único marco, por su globalidad y sistematización, en el que cobraban verdaderamente sentido las tareas de ampliación de estudios en el extranjero y de documentación técnica en que la Junta había acumulado su experiencia, pero que al mismo tiempo subordinaba su actuación al desarrollo de políticas estatales de radio más extenso y decisivo. La separación ulterior de todo lo relacionado con las pensiones de ampliación de estudios para los ingenieros no fue más que un corolario inevitable, coherente con el desarrollo reglamentario de aplicación del Estatuto, que estableció una fórmula orgánica diferente a los distintos grados de la formación técnica y dejó definitivamente a la Junta de Pensiones en el ámbito, extraordinariamente ambicioso en sus objetivos, de una integral formación profesional obrera. Pero esto fué ya en los prolegómenos de la experiencia política republicana, en cuya tormenta política la callada labor de la Junta de Pensiones -en este momento ya fraccionada en dos entidades: el Centro de Perfeccionamiento Profesional Obrero y la Oficina Central de Documentación -apenas logró mantenerse a flote.

\section{Contexto de partida, 1901-1907}

Regeneracionismo, europeísmo, nacionalismo, populismo son conceptos clave vinculados al complejo mundo intelectual de la España 
de final del siglo XIX sobre los que sería una redundancia insistir, recientes como están las copiosas reflexiones inspiradas por la efemérides del 98. A todos ellos, incluso a sus potencialidades contradictorias, les subyace, sin embargo, una preocupación de orden teórico y práctico común: la educación. Difícilmente se encontrará una propuesta reformista, del género que sea de entre las múltiples colocadas en la palestra pública por aquellas fechas, que no contenga su correspondiente capítulo dedicado a ponderar la necesidad de educación interior y de enseñanza pública del pueblo español como instrumento privilegiado para proporcionarle de nuevo el rumbo nacional perdido y para colocarle en pie de igualdad con el resto de los pueblos europeos.

La creación del ministerio de Instrucción Pública y Bellas Artes en 1900 y la política educativa de sus primeros ministros -de García Alix y Romanones especialmente- constituyó el mejor testimonio de que estas demandas sociales intentaban además convertirse en política oficial. En general, todos los campos educativos estuvieron en el punto de mira de la política reformista, aunque ciertamente con muy diversos resultados. De todos ellos resulta aquí pertinente el referido a la enseñanza técnica y profesional. Lo más general que de ella se puede decir es que fue un ámbito de conocimientos de escasa demanda pública y de menor aún atención política. Las primeras escuelas superiores técnicas constituidas en el siglo XIX -las de ingenieros de Caminos, Minas y Agrónomos- se orientaron predominantemente a proveer de personal burocrático a los respectivos cuerpos técnicos estatales y sólo subsidiariamente al servicio de la empresa privada. La única de ingeniería industrial fue la de Barcelona, de iniciativa local, hasta la constitución a final de siglo de la de Bilbao, de idéntico carácter ${ }^{2}$. En los niveles intermedio y bajo, sólo una no muy copiosa red de Escuelas de Artes y Oficios, de Bellas Artes y de Peritaje de titularidad estatal, local o privada abasteció el mortecino mercado de trabajo técnico, de forma que, con carácter general, se puede decir que durante todo el siglo fue más bien el empirismo propio de las etapas iniciales de la industrialización el que predominó en España en la formación de la mano de obra artesanal e industrial, y allí donde el desarrollo de la industria imponía una mayor especialización, se optó por la utilización de técnicos titulados de los países inversores. Resultan muy significativas a este respecto las cifras proporcionadas por una encuesta ordenada por el ministro, conde de Romanones, en 1901, como base de sus proyectos de reforma en este campo, según la cual trabajaban en la industria española en aquel momento 1386 técnicos extranjeros de diversa titulación, originarios de 12 países europeos, y aun para que 
los datos se aproximasen a la verdad, según el ministro, habría que agregar «un $50 \%$ a las cifras globales» ${ }^{3}$.

El problema de la enseñanza profesional comenzaba, en efecto, a convertirse en una cuestión relevante dentro del regeneracionismo pedagógico de comienzos de siglo. La política al respecto de los dos primeros ministros de Instrucción Pública se orientó, por una parte, a equilibrar los estudios humanísticos clásicos de los Institutos con nuevas disciplinas de carácter técnico y a reordenar globalmente los ciclos medio y bajo de toda la enseñanza profesional existente. El conde Romanones llegó incluso a integrarlos en unos recreados Institutos Generales y Técnicos ${ }^{4}$ que respondiesen, según decía en la Exposición, «a las necesidades tan varias como son las de la moderna vida comercial, industrial y científica», aunque la duración de la reforma no llegó a sobrepasar la etapa ministerial de su sucesor en el cargo. De la reforma permaneció vigente, no obstante, la tercera escuela de Ingenieros Industriales, la Central, creada en el mismo decreto de Romanones como culminación de la reorganización integral de la enseñanza técnica prevista.

Pero la política educativa en este campo se orientó también a promover la relación del universitario español con sus homólogos extranjeros, que es el terreno específico en que quiere centrarse el presente trabajo. Por R. D. de 18 de julio de $1901^{5}$ de Romanones, en efecto, se crearon pensiones de 4000 ptas. anuales, más gastos de viaje, para los alumnos más aventajados de las Facultades de Derecho, Medicina y Farmacia, de las Secciones, por turno, de Ciencias y Filosofía y Letras, de las Escuelas Normales Centrales de Maestros y Maestras y de las Escuelas de Ingeniería, todas ellas igualmente por turno. Serían los Claustros o Juntas de esas instituciones los encargados de determinar las materias objeto de estudio y los lugares de residencia de los pensionados, así como de dictaminar la memoria reglamentaria de fin de pensión. Su pronunciamiento favorable daría al pensionado la posibilidad de renovar la beca por un año más y el derecho a ocupar la primera vacante de profesor auxiliar que solicitare.

El mismo decreto, por otra parte, facultaba al Gobierno para conceder permiso a los profesores numerarios, auxiliares y supernumerarios de los mismos centros, uno como máximo por cada Facultad, Sección o Escuela, para residir en el extranjero durante un año con todo su sueldo más alguna subvención suplementaria si lo permitiesen los créditos disponibles, a fin de ampliar estudios en sus respectivas disciplinas. La memoria ulterior de sus resultados podría servir, por informe favorable del Consejo de Instrucción Pública, como mérito en su carrera.

Los cambios políticos no afectaron en este caso a la política del ministerio. El siguiente ministro, el conservador Gabino Bugallal com- 
plementó dos años después el anterıor decreto con una propuesta precisa de la subvención debida al profesorado -3000 ptas. anuales- y con una ampliación de los centros beneficiados por esta política -entre los nuevos: los Institutos, las Escuelas de Artes e Industrias y de Industrias y Artes Industriales, las de Comercio, las de Veterinaria y las nuevas Secciones de las Facultades de Ciencias y de Filosofía y Letras creadas en la reciente reforma de dichas Facultades- estableciendo además la obligación para los profesores pensionados de impartir en el curso siguiente una lección semanal sobre el tema objeto de su perfeccionamiento en el extranjero.

Las becas para los alumnos más destacados de esos mismos centros, excepción hecha de los de los Institutos, fueron también objeto de una normativa más precisa: su atribución sería el resultado de una oposición y los resultados positivos de la experiencia en el extranjero daría el derecho, ya no a las plazas de auxiliar numerario, sino al nombramiento de auxiliar sustituto personal del profesor del Centro, correspondiente al grado de enseñanza y la materia objeto de la pensión, con derecho a percibir la gratificación correspondiente a las plazas vacantes de auxiliares retribuidos y a concurrir a las oposiciones del turno de auxiliares de las cátedras numerarias del profesorado correspondiente. La novedad más importante fue, sin embargo, la inclusión en la convocatoria de dos alumnos obreros por las Escuelas de Artes e Industrias y otros tantos por las de Artes Industriales e Industrias, a propuesta de los Claustros respectivos. Para los alumnos beneficiados sería mérito preferente para la provisión de plazas de ayudantes de maestros de talleres de su respectiva especialidad ${ }^{6}$.

Podría decirse, por consiguiente, que las orientaciones enunciadas por estas normas sobrepasaban el marco de la política partidista y de la actuación de un ministerio para emplazarse en un amplio consenso de opinión pública sobre la necesidad de un cambio de rumbo de la enseñanza pública hacia las disciplinas empíricas y técnicas y hacia un mayor contacto académico y universitario con el exterior. Estos objetivos habían inspirado, por ejemplo, una persistente línea informativa del periódico El Imparcial desde 1899, al poner de relieve la escasa rentabilidad económica de los títulos clásicos frente a las enseñanzas técnicas y la ventaja comparativa que para las clases medias significaba la opción de enviar a sus hijos a centros de enseñanza técnica en el extranjero, a Bélgica, Suiza, Francia e Inglaterra especialmente. Esta campaña se mantuvo en comentarios editoriales a lo largo de los años 1900, 1901 y 1902. Los objetivos concordaban perfectamente, por otra parte, con la opinión de las propias organizaciones 


\section{La Junta de Pensiones de Ingenieros y Obreros....}

profesionales expresada en las sucesivas convocatorias corporativas, como fue el caso de la Asamblea General de Amigos de la Enseñanza de 1901 y en las Asambleas Universitarias de 1902 y de 1905. En la primera se pedía incluso que esa relación científica con el extranjero se institucionalizase en un centro de estudios industriales prácticos con una bien dotada biblioteca, laboratorios y gabinetes de experimentación e investigación, localizado, a ser posible, en los Estados Unidos de Norteamérica, en un ambiente de plena integración en las más avanzadas corrientes del desarrollo industrial ${ }^{7}$.

Pues bien, en plena sintonía con estas corrientes de opinión públicas y privadas una R. O. de 22 de septiembre de $1903^{8}$, esta vez del ministerio de Agricultura, Industria, Comercio y Obras Públicas, convocó cien pensiones para obreros manuales a fin de que pudiesen ampliar sus conocimientos en Francia y Bélgica durante dos años, prorrogables por uno más a propuesta del ingeniero jefe de la expedición, de los dos que, conforme a la disposición, debían estar al frente de ella. Las solicitudes, añadía la R. O., irían acompañadas de informe favorable de una sociedad obrera o industrial, de las Escuelas Industriales y de Artes y Oficios o de las Cámaras de Comercio o Agrícolas y la selección estaría a cargo de una Junta presidida por el Presidente de la Junta de Reformas Sociales e integrada, además, por el director de la Escuela Superior de Industrias, presidentes de la Cámara de Comercio, Unión de la Unión Mercantil, Fomento de las Artes, Círculo Industrial, Centro Instructivo del Obrero, Centro de Sociedades Obreras de Madrid, así como de los presidentes de las ocho sociedades obreras más antiguas y de las cuatro más modernas.

\section{La Junta, 1907-1924}

Se puede decir que esta disposición fue el punto de arranque de la experiencia pública que historiamos. El éxito de la convocatoria sorprendió a los propios organizadores. Durante los meses siguientes llegaron al ministerio 1220 solicitudes desde casi todas las provincias y desde la mayor parte de los sectores profesionales ${ }^{9}$. Con su selección comenzó la andadura inicialmente vacilante de una experiencia sin ninguna duda extraordinariamente novedosa en su momento. Las ulteriores etapas fueron precisamente de revisión de los resultados obtenidos y de modificación de sus principales desajustes. El balance en todo caso fue tan lisonjero como para llegar a convertirse en una línea permanente de la política de Fomento. Lo decía el ministro Augusto González Besada al firmar el decreto de $16-\mathrm{VI}-1907^{10}$, que la ratificaba, 
con las modificaciones exigidas por la experiencia de la primera expedición. Tales cambios coincidían en síntesis con las recomendaciones expuestas por los dos ingenieros responsables de aquélla, Enrique Sanchís y Ernesto Winter: la necesidad de preparar con mayor detenimiento la expedición y de agilizar la etapa previa de colocación de los pensionados en el extranjero, la conveniencia de seleccionar algunas industrias merecedoras de atención prioritaria, la exigencia de garantizar la vuelta del beneficiado a España tras el plazo previsto de pensión ${ }^{11}$. De esta forma, la nueva expedición propuesta se confiaba a la responsabilidad de un mayor numero de pensionados ingenieros -cinco por cada una de las Escuelas de Minas, Montes y Agrónomos-- se establecían unas industrias de atención prioritaria (metalúrgica, electricidad, automóvil, maquinaria, viticultura y derivados de la leche, textiles, tintorería y estampados de tejidos, fotograbado, estampación, fototipia y litografía y vidrio), y finalmente se determinaba que los jornales de los obreros serían retenidos íntegramente para su reintegración tras el regreso a España y cumplidos todos los compromisos contraídos con los lugares de trabajo de origen. Un centro administrativo, localizado en Ginebra, se encargaría de coordinar la gestión económica y organizativa exterior de las becas.

El diseño definitivo de esta experiencia estatal se producirá en los años sucesivos, como decantación práctica de las ulteriores expediciones de pensionados. En 1910 se dispuso la división del período de pensión en dos fases, la primera de ellas de iniciación en España asistiendo a cursos de lengua francesa y de tecnicismo industrial o análogos, a juicio de una Junta de Patronato de Pensiones que ahora se creaba. Por su parte, el centro gestor en el extranjero se transfería a Bruselas o Lieja, con una delegación en París ${ }^{12}$. Finalmente, en 1913 se daba a todo este proceso una ordenación mas precisa en lo referente a la convocatoria, colocación, formación y seguimiento de los pensionados a su regreso a España. En concreto, el R. D. de 4-IV ${ }^{13}$, de Miguel Villanueva disponía que la Junta se encargase de proponer las industrias prioritarias, el número de pensionados y la distribución provincial para realizar a continuación la convocatoria oficial; se señalaba a un inspector ingeniero como responsable máximo de toda la gestión, en contacto con los centros de Bélgica y Francia y con cuatro comisionados extranjeros, a proponer por la Junta, como gestores de la colocación de los obreros en las fábricas y talleres existentes en su respectiva jurisdicción.

Bajo estas normas comenzó la Junta de Patronato de Ingenieros y Obreros en el Extranjero a acumular su experiencia y a poner los 
primeros jalones de un patrimonio material y humano que no tardara en serle precioso. Desde 1916 comenzó a publicar una revista, el Boletín de la Junta de Pensiones de Ingenieros y Obreros en el Extranjero (BJPIOE), órgano de seguimiento de los pensionados, de consejos prácticos para su mejor desenvolvimiento y de publicación de las memorias finales de los ingenieros y obreros pensionados.

Pero antes de entrar en mayores detalles acerca de las experiencias concretas de la Junta y de sus pensionados tal vez convenga detenerse un momento en lo que denominaríamos la filosofía práctica, sin duda de neta raíz institucionista, que les sirvió de norte y en algunas reacciones que sus iniciativas despertaron desde primera hora. Pueden servirnos de guía los Consejos a los pensionados recogidos en uno de los primeros números del Boletín. En resumen, esa filosofía podría compendiarse en los términos ver, aprender y relacionarse. En último extremo, no se trataba tanto de una iniciativa de estricto perfeccionamiento profesional cuanto de abrirse a un nuevo espíritu de inquietud intelectual y de innovación técnica. Ver era en consecuencia una disposición intelectual tan importante como la propia experiencia profesional: «abrir los ojos» en los viajes, en las visitas a las fábricas, en las excursiones, en la observación de los escaparates, en la vida al aire libre («nunca se pierde el tiempo al aire libre»). En cualesquiera de estas circunstancias en apariencia anodinas se podían descubrir aspectos de interés de potencialidades insospechadas para la vida profesional futura. Junto a la observación despierta y vigilante, el cultivo de las relaciones personales era la segunda disposición de espíritu exigida para que la estancia en el extranjero resultase provechosa para la formación y perfeccionamiento profesional del pensionado; una formación con la perspectiva que daba el conocimiento vivido y contrastado en múltiples experiencias personales, y no sólo obtenido a partir de los libros, que podían ser instrumentos muy útiles para sembrar ciencia, metodizar conocimientos, enseñar a pensar, pero que no tenían el vigor, «la fuerza que da la palabra», «que sólo en la vida, en el diario comercio con otras personas» se lograba. Relacionarse con los naturales del país, cultivar la amistad con las gentes de su oficio, hablar con profesionales cualificados en las distintas ramas profesionales eran, aparte sus potencialidades formativas, aptitudes vitales modeladoras de la autoestima y la autonomía personal, tan importantes como los propios conocimientos profesionales adquiridos ${ }^{14}$. A diez años vista de estos consejos la experiencia de uno de los primeros responsables de las expediciones obreras, Ernesto Winter, confirmaba lo acertado de estas observaciones. Si algunos patronos, si algunos obreros habían 
esperado inicialmente de las pensiones secretos milagrosos de fabricación o una predestinación especial de ascenso social, con cierta frecuencia se habían sentido decepcionados ante el sistema de producción fabril del momento en que los procedimientos científicos habían sustituido ya a los empíricos. Pero si no remedios productivos milagrosos, los pensionados habían obtenido, en cambio, algo que no habían previsto y que había resultado a la larga igualmente fructífero: «el espíritu investigador, la iniciativa ${ }^{15}$.

Un planteamiento formativo tan abierto -como el que, en general, informó el ideario institucionista, en el que sin duda alguna se insertabaatrajo hacia sí las mismas opiniones encontradas que merecieron todas sus obras y que, con parecidos términos, sufrió la Junta de pensiones por antonomasia, la de Ampliación de Estudios. El mismo gestor antes mencionado ponía a esas objeciones nombres y apellidos, definiendo arquetípicamente el papel potencialmente contradictorio en que podía enmarcarse la tarea de la Junta: un profesor -contaba- le había indicado la conveniencia de proponer al gobierno la supresión de las pensiones y la fundación de Escuelas profesionales o la mejora de las existentes; el general Cubillo, que las pensiones sólo servían para «estropear obreros», que volvían del extranjero con ideas socialistas y anarquistas; Largo Caballero, que todo pensionado era una persona perdida para la lucha ${ }^{16}$. Que estas alternativas no eran hipótesis teóricas sino que se estaban jugando en la vida cotidiana de los pensionados lo testifica la polémica que acompañó la primera expedición a resultas de algunos artículos publicados en el periódico España Nueva en febrero y marzo de 1907, obra de un exilado bien conocido en los medios anarquistas parisinos, calificando la experiencia de pérdida de tiempo y malversación de fondos y denunciando el falseamiento de los resultados obtenidos ${ }^{17}$.

Posiblemente, es cierto, tenía mucho del utopismo pedagógico e interclasista un poco ingenuo que acompañó todas las iniciativas acometidas por el institucionismo, aparte las dificultades prácticas de primera hora para gestionar una experiencia que dependía en buena medida de la colaboración hasta cierto punto desinteresada de empresas e instituciones extranjeras, y más delante de los problemas derivados de la guerra europea, pero eso no fue obstáculo para que el balance fuera en general positivo. Observémoslo con mayor detenimiento a partir del informe publicado acerca de las tres primeras expediciones gestionadas por la Junta, es decir, las de 1911, 1914 y 1917, comenzando por lo que respecta a los obreros. Sesenta y ocho habían iniciado la primera expedición, en las tres amplias ramas prioritarias de la convocatoria (industria textil, mecánica y electricidad, agricultura, viti- 
cultura, oleicultura e industrias derivadas de la leche y curtidos y papelería) de los que nueve desistieron más o menos rápidamente por enfermedad o por voluntad propia. De los restantes, tan sólo cuarenta tuvieron una colocación permanente y 28 llegaron a publicar el informe científico de final de pensión. La segunda expedición comenzó con 50 pensionados de las especialidades de agricultura e industrias derivadas, mecánicos y electricistas, papeleros, artes gráficas, curtidores y textiles, de los que cuatro desistieron al poco de comenzar la guerra europea. Treinta y uno presentaron sus trabajos finales, la mayor parte de ellos publicados en el Boletín. Por último, compusieron la tercera expedición 46 pensionados, entre agricultores, trabajadores del textil, dibujantes de muebles, artes gráficas, electricistas, mecánicos, un relojero y un orfebre, y sus resultados estaban todavía por ver en el momento del informe. Contando con las deficiencias que es posible entrever a partir de estos datos, y con el hecho asimismo de que algunos de los expedicionarios habían decidido permanecer en el extranjero, el resultado final había sido, sin embargo, muy positivo. Buena parte de los pensionados -datos concretos de cuarenta y cinco de ellos recoge el informe- habían aprovechado la estancia en el extranjero para completar su formación teórica, cursando estudios o asistiendo a cursos en Escuelas o Laboratorios especializados de Bélgica, Francia, Alemania, Inglaterra e Italia. Muchos de ellos habían logrado obtener puestos destacados en España a su regreso, bien es cierto que con dificultades en los primeros momentos y no sin un activo seguimiento y apoyo por parte de la Junta. Sumando los nombres de las dos primeras expediciones, quince de ellos se habían establecido por su cuenta a su regreso a España, otros cinco habían ampliado talleres, fábricas o negocios pertenecientes a sus padres y veinte ocupaban cargos de directores de fábricas y contramaestres, más otros cuatro que ocupaban puestos equivalentes en el extranjero.

En cuanto a los ingenieros de las especialidades de minas, agrónomos y montes, sesenta y seis habían disfrutado de pensión entre 1912 y 1917 recorriendo instalaciones agrícolas e industriales de Francia, Suiza y Alemania especialmente; de Estados Unidos, Italia, Inglaterra y Bélgica en menor medida y de Polonia, Suecia, Argentina y Túnez en algún caso. Sin duda, su actividad no había estado tan controlada como la de las expediciones obreras, pero al cabo se podía también contabilizar un número significativo de estudios prácticos resultado de sus experiencias en el exterior ${ }^{18}$.

En resumen, todo parece indicar que a lo largo de estos años, nada propicios por lo demás para la normal relación con los países 
europeos próximos, dada la situación de guerra, la Junta logró fijar una práctica gestora autónoma y una red de contactos y relaciones en el mundo académico y empresarial de esos países, que terminó por corregir la inevitable improvisación de los primeros momentos. Años más tarde, en 1924, aparecerán algunos de estos nombres -hasta cuarenta y tres, junto a sus razones sociales- en una R. O. comunicada del 2 de diciembre del Ministerio de Estado agradeciéndoles la labor realizada en apoyo de los obreros pensionados ${ }^{19}$. $\mathrm{Y}$ ni mucho menos eran la mayoría en la trama de relaciones tejidas, pero sí los que aparecían más repetidamente en la relación de destinos de las ciudades más solicitadas: París, Lieja, Bruselas, Amberes, Lyon, Burdeos, Grenoble, Billancourt.

Con esta experiencia decantada, en efecto, a la altura de 1921 la Junta se sentía con recursos para abordar nuevos objetivos. Un decreto de ese año del ministerio de Trabajo, al que la Junta había sido transferida en 1920 al crearse el departamento ${ }^{20}$, reorganizó el conjunto de las atribuciones de la entidad dentro del nuevo ministerio. Era en síntesis una ratificación de sus competencias tradicionales, pero lo más esencial concernía al reforzamiento de sus facultades de autonomía administrativa, una de sus más destacadas bazas tradicionales -así lo evaluaba una ponencia presentada en el Congreso de Ingeniería de $1919^{21}$ - al establecer la posibilidad de gestionar, aparte las dotaciones presupuestarias oficiales, fondos propios procedentes de los bienes adquiridos, de la venta de publicaciones o de donaciones. Por lo demás, los beneficios de la pensión se ampliaban a otros colectivos profesionales hasta entonces relegados, como los ingenieros industriales, peritos mecánicos, electricistas y químicos, ayudantes de los Cuerpos de ingenieros $\mathrm{y}$, en general, cualquier técnico, con títulos o sin ellos, de probada capacidad. Se abría, por lo demás, una nueva línea de pensiones para seguir cursos profesionales en España y se le otorgaba a la Junta la posibilidad de organizar cursos de perfeccionamiento profesional para obreros por iniciativa propia o a petición de entidades patronales, corporaciones o sindicatos, utilizando como profesores de preferencia a ingenieros y obreros antiguos pensionados ${ }^{22}$.

Estas nuevas iniciativas, en realidad, no venían sino a ratificar y extender unas experiencias ya en marcha. Desde 1920, en efecto, se había organizado en la sede de la Junta una Biblioteca y un servicio de información bibliográfica técnica, que si hacia mediados de ese año contabilizaba la suscripción a 146 revistas, en su mayoría extranjeras ${ }^{23}$, a comienzos del año siguiente ascendían ya a 343 , junto con un fondo bibliográfico de 4377 volúmenes ${ }^{24}$, y sólo unos años más tarde este 


\section{La Junta de Pensiones de Ingenieros y Obreros....}

patrimonio había crecido considerablemente hasta alcanzar la cifra de 9686 libros y 578 suscripciones, con un almacén de 56.825 números $^{25}$. En esa misma época las fichas de documentación técnico-bibliográfica existentes en la sección ascendían a $19.860^{26}$, considerable volumen de utilísima información sobre los principales artículos insertos en las revistas, relaciones bibliográficas, patentes, etc. Todo parece indicar que la Biblioteca se habían convertido en un centro habitual de consulta de las novedades bibliográficas técnicas por parte de estudiantes, profesionales y obreros especializados. En efecto, tomando como referencia los datos de 1926, habían pasado por la sección 9233 lectores, consultando 14312 volúmenes, más otros 2638, que habían realizado la consulta de 4203 revistas $^{27}$. Si de estas cifras pasamos a las del primer semestre de 1929, después de que a comienzos de noviembre de 1927 se ampliase el servicio de consultas a las mañanas, podremos comprobar el extraordinario asentamiento de la sección: sólo en la primera mitad del año la Biblioteca había contado con la presencia de 10415 lectores de libros (18.665 consultados) y 3569 de revistas (5410 utilizadas) ${ }^{28}$.

Fuera de las actividades oficiales, por otra parte, desde 1920-21 se comenzó a organizar una Asociación de Obreros Expensionados. El mantenimiento del espíritu de cordialidad y franca amistad de las relaciones trabadas fuera de España, con ser el primero de sus objetivos, no era, sin duda, el más decisivo. Primaba en particular el de hacer valer ante los centros de trabajo los conocimientos adquiridos en el extranjero, así como revalorizarlos en una labor sistemática de difusión, orientación y colaboración en las tareas de la Junta ${ }^{29}$. A partir de abril de 1924, tras varias intentonas fallidas, la Asociación pudo darse, en efecto, por constituida, de forma que desde mayo contaba ya con un órgano periodístico propio: el Boletín de la Asociación de Españoles Pensionados y Expensionados en el Extranjero, aunque la aprobación oficial de su reglamento no se produjese hasta mediados del año siguiente. Contaba por entonces con 52 asociados, más 42 adheridos $^{30}$. $\mathrm{Su}$ primera iniciativa fue la de organizar cursos de idiomas en el local de la Junta, pero bien pronto, conforme a los proyectos iniciales, comenzó a organizar cursos y conferencias en ese mismo centro y en la Casa del Pueblo de Madrid, creó una Bolsa de Trabajo y emprendió algunas iniciativas de defensa de la mano de obra técnica nacional frente a la competencia de los técnicos extranjeros ${ }^{31}$.

En estas iniciativas, confluyó, por lo tanto, con las nuevas inquietudes de la propia Junta, lo que fue asentando algunas nuevas actividades regulares de la institución, con esa característica tan singular de autogestión de los recursos y de lancasterismo pedagógico de todas 


\section{Francisco Villacorta Baños}

sus tareas. Los cursos de idiomas, en primer término. En 1923 asistían regularmente a las enseñanzas de francés e inglés 86 alumnos obreros ${ }^{32}$; en 1925 , concluyeron los cursos 142 de los 202 iniciales $^{33}$; los cursos de perfeccionamiento profesional y los cursos de iniciación matemática y mecánica impartidos en la propia biblioteca y con finalidad eminentemente práctica de facilitar el manejo de los fondos documentales acumulados.

\section{Contexto final, 1924-1936}

Todo lo anterior planteado como complemento formativo de los pensionados y expensionados, ciertamente, pero cuyo precipitado esencial era ya el de un nuevo impulso de formación integral técnica y profesional, tal y como se iba a diseñar en la legislación del Directorio Militar a partir de 1924. En el Estatuto de Enseñanza Industrial de 31 de octubre de ese $a n 0^{34}$, en efecto, la labor realizada por la Junta de Pensiones quedaba enmarcada en el capítulo VIII referente a los estudios de investigación y de ampliación de las Escuelas de Ingenieros y de Peritos industriales. Estas Escuelas, así como una Comisión Permanente de Enseñanza Industrial y las respectivas Juntas regionales que ahora se creaban podrían establecer, de acuerdo con sus presupuestos, estudios de investigación industrial o de ampliación de materias. Entre las entidades que adquirían de facto la categoría de Institutos oficiales de ampliación de estudios e investigación industrial estaba la Junta de Pensiones, (art. 49), que seguiría sostenida por el Estado (art. 51) y a la que se le reservaba unas más amplias e importantes funciones enmarcadas en al menos dos aspectos de la labor que venía gestionando hasta entonces. Tenía que ver el primero con su originaria proyección exterior, pero en un sentido mucho más amplio que el de la estricta formación o perfeccionamiento profesional. El artículo 52 del mencionado capítulo VIII del Estatuto preveía, en efecto, la creación de Residencias obreras en el extranjero, que tendrían por objeto: a/ constituir un centro de orientación y preparación para los grupos de pensionados que el Estado, las Escuelas o las Corporaciones pudiesen enviar al extranjero; b/ organizar o fomentar la enseñanza complementaria de carácter general o profesional anexa a los grandes núcleos de obreros emigrantes de acuerdo con la Dirección General de Emigración; c/ fomentar la creación de agrupaciones locales allí donde la acción directora de la Residencia no se pudiese ejercer $\mathrm{y} \mathrm{d} /$ constituir focos de cultura general que, a la vez que cumpliesen sus fines propios, sirvieran de enlace del trabajador emigrante con su país, preparando de este modo su 


\section{La Junta de Pensiones de Ingenieros y Obreros....}

regreso en las condiciones más ventajosas. Pues bien, estas Residencias serían organizadas por la Junta de Pensiones en los lugares y forma que ella determinase y en proporción a los medios económicos atribuidos por el Estado o los particulares. Asimismo, para difundir el objetivo principal de estas Residencias sin multiplicar su número, la Junta de Pensiones podría pensionar a maestros nacionales, que con destino en ellas y preparados en el ambiente extranjero y en contacto con la realidad y las necesidades culturales del obrero emigrado, pudieran servir de enlace entre las Residencias y los pequeños grupos de emigración diseminados por diversos países. Podría asimismo la Junta, conforme al artículo 54, contribuir al intercambio de profesores españoles y extranjeros de enseñanza industrial.

El segundo aspecto se relacionaba con la más reciente tarea de formación del obrero calificado dentro del país. Así, junto a las Escuelas mencionadas, la Junta podría organizar o estimular cursos de especialización de enseñanzas prácticas en técnicas poco conocidas, en colaboración con entidades interesadas y con el concurso de técnicos y obreros, nacionales o extranjeros, así como pensionar a personas para adquirir dichas técnicas en el exterior.

Fue a partir de esta última base como la Junta encontró su último emplazamiento funcional, ya definitivamente en el campo de la formación profesional obrera. El Estatuto de Formación Profesional de 1928, en efecto, atribuyó este proyecto integral de enseñanza profesional primaria y media a centros de formación -en los que se incluían las oficinas-laboratorios de orientación y selección profesional y el preaprendizaje, las Escuelas de trabajo industriales y artesanas y las Escuelas de técnicos industrialesy a instituciones de perfeccionamiento, bien a través de centros profesionales en España o en el extranjero, de centros de documentación profesional o centros de estudio y aplicación de fisiología del trabajo, psicotecnia y organización científica del trabajo. Pues bien, la Junta pasaba a partir de ahora a integrarse en esta última red bajo el nombre de Junta Central de Perfeccionamiento Profesional Obrero, del mismo modo que su servicio de información bibliográfica adquiriría entidad oficial como Oficina Central de Documentación Profesional, con filiales provinciales, a la que se atribuía la responsabilidad de publicación de un nuevo órgano denominado Revista de Formación Profesional. En contrapartida -y esta era la otra cara de definitivo anclaje de la Junta- se retiraba de sus atribuciones todo lo referente a las pensiones de ampliación de estudios e investigación de los ingenieros que hasta entonces detentaba ${ }^{35}$.

Pero con ser importantes no eran esos cambios los de mayor trascendencia. En la medida en que sus atribuciones se subordinaban a 
un proyecto político integral de formación profesional obrera, la Junta venía al mismo tiempo a perder el grado de espontaneidad organizativa y de autonomía gestora que habían sido su grandes activos hasta entonces. De hecho, a partir de este momento va a entrar en una dinámica de cambios en su organización interna y en su dependencia orgánica, que buscaban incardinar su función tradicional en aquellas políticas estatales de más amplio radio, algo que se reforzará aún más con las transformaciones legislativas de la etapa republicana. En su dimensión exterior, en primer término, vinculada a los prolegómenos de una política de asistencia a la emigración, como más atrás sugerimos. Es muy significativo al respecto, además, que el Ministerio de Asuntos Exteriores tomase a partir de 1927 la iniciativa de interesar al Embajador español en París acerca de la suerte de los pensionados en la república vecina con el fin de facilitarles los trámites administrativos ante las autoridades francesas del trabajo y ante los responsables de las empresas. En esta misma línea comenzó a estudiarse en el Ministerio los términos de un acuerdo sobre el intercambio de «stagiaires» (trabajadores estacionales) entre España y Francia, en términos parecidos a los ya firmados por esta nación con, al menos, Gran Bretaña, Alemania y la Comisión de Gobierno del Sarre. El proyecto de acuerdo, concluido a comienzos de 1930, fue remitido al ministerio de Trabajo e informado por la Junta en mayo de ese año, con numerosos añadidos y puntualizaciones, fruto de su experiencia pasada en la gestión pública y privada del trabajo de los pensionados, cada vez más sujeto a las trabas reglamentistas del ministerio de Trabajo francés. Y aunque la mayor parte de estas consideraciones fueron asumidas por el centro ministerial español, posiblemente desde la otra parte, dado el desequilibrio de los intercambios de mano de obra, no se estaba dispuesto a llegar demasiado lejos en esa política, ya que un año después el Gobierno francés comunicaba al Embajador español en París su deseo de atenerse a la redacción primitiva del convenio, lo que, unido a los avatares del cambio de régimen en España, terminará por agostar la iniciativa ${ }^{36}$.

En segundo lugar, en su faceta interior, sin duda la más decisiva en esta etapa, vinculada a la política de formación obrera y a la legislación reformadora republicana, en medio de las cuales terminaría por naufragar hasta cierto punto el viejo utopismo institucionista de pedagogía social y de autonomía de las iniciativas cívicas, incluso de las cobijadas bajo el manto del Estado. Es cierto que la Junta mantuvo sus facultades y su política tradicional formativa, estrechamente vinculada a la demanda de trabajo industrial. En su informe de julio de 1931 proponiendo los pensionados de la convocatoria de febrero de 
aquel año ratificaba expresamente su singularidad tradicional en el campo del «perfeccionamiento», y no de la «formación profesional, por lo que la pensión ha de recaer sobre un obrero selecto ya formado en el oficio o bien que tenga actitudes excepcionales». El criterio de «exigencia social» que presidía la pensión, que no el beneficio ni la recompensa individual, era el que guiaba la selección de los pensionados hacia los oficiales especializados -no siempre a favor de los mejor formados, «si el oficio /era/ corriente»- hacia las industrias de reducida magnitud, que requerían más la ayuda del Estado y, en igualdad de condiciones, hacia los trabajadores procedentes de regiones de tradición industrial, donde la formación adquirida tendría más posibilidades de desarrollarse ulteriormente ${ }^{37}$. Pero no resulta muy aventurado suponer la endeblez de estos objetivos ante las grandes cuestiones políticas que se abrirán muy pronto a la España republicana, ante las dificultades de financiación estatal que cerraban la década e incluso ante la propia compulsión reformadora republicana. La convocatoria de pensiones siguió publicándose regularmente, cierto que casi nunca para las 45-50 que la Junta había considerado siempre precisas, y en número decreciente conforme la mencionada coyuntura obligaba a reducir el presupuesto estatal y conforme se hacían presentes las urgencias de los pensionados ante la depreciación de la peseta ${ }^{38}$. Igualmente, la desorientación provocada por los cambios de la legislación educativa dictatorial y posteriormente por el cambio de régimen político sacudió duramente a la Junta. Así, a mediados de 1930 pasó a convertirse en una dependencia ministerial, bajo el nombre de Centro de Perfeccionamiento obrero, con su Oficina Central de Documentación Profesional; fue transferido después al Ministerio de Instrucción Pública, junto con todo el resto de atribuciones de enseñanza emplazadas hasta entonces en los ministerios de Trabajo y Economía Nacional, pasó dentro de aquél a depender inicialmente de una Comisión de Formación Profesional, más tarde de una Sección de Formación Profesional afecta a la Dirección general de Enseñanza Profesional y Técnica creada poco antes, de la Subsecretaría del ministerio desde 1935 y de nuevo de la recreada Dirección General desde el año siguiente, ahora denominada de Segunda Enseñanza y Enseñanza Superior ${ }^{39}$. El propio centro se vio sometido a algunos cambios organizativos menores, que si algo indicaban era precisamente esa misma subordinación funcional a una concepción política dirigista muy diferente de la que había primado en la mayor parte de los años más fecundos de la Junta. Los servicios de la Oficina de Documentación pasaban a distribuirse en 1934 en cuatro secciones diferentes (bibliográfica, de información mecánica, quí- 
mica industrial y electrotecnia) y poco después adquirían autonomía respecto al Centro de Perfeccionamiento encargado de las pensiones ${ }^{40}$. Significativo de estas nuevas formas de actuación a que se vio avocada la Junta fue el hecho de que durante algunos meses de 1929, muy pocos, conviviesen dos revistas de equivalentes intereses y contenido: el viejo Boletín -desde 1929 reconvertido en Boletín de la Junta Central de Perfeccionamiento Profesional Obrero- y la Revista de Formación Profesional creada oficialmente en el Estatuto de 1928, para, como no podía ser de otra forma, desaparecer inmediatamente ambas.

En medio de todo ello, la Junta, que había surgido para abrir las ventanas hacia el exterior, perecía en el peor de los ensimismamientos colectivos: el de una guerra civil, y su labor de contrastación sistemática de experiencias formativas y laborales del personal técnico superior y obrero español con sus equivalentes europeos se cerraba momentáneamente para sólo reaparecer más tarde, en otro contexto, bien a merced de las leyes de la oferta y demanda de mano de obra, la emigración, bien a la lenta recuperación de todas estas redes de relación tejidas desde comienzos de siglo.

\section{Notas}

1 Basta echar un vistazo al recuento historiográfico de los últimos años para certificarlo. Al respecto, Historia de la educación en la España contemporánea. Diez años de investigación. Edic...: J.-L. GuereñA, J. Ruiz Berrio, A. Tiana Ferrer. Madrid, C.I.D.E, 1994.

2 Se creó por R. D. de 2-IV-1897, pero no tuvo funcionamiento real hasta el Reglamento de 5-I-1899, Gaceta, 6-I. Ciertas presiones dentro de la propia profesión estuvieron en la base del retraso, según GARRABOU, R. (1982): Enginyers, industrials, modernització econòmica $i$ burguesia a Catalunya (1850-inicis del segle XX). Barcelona, p. 43.

3 Datos publicados por R. O. 10-VII-1901, Gaceta, 12-VII.

4 R. D. de 17-VIII-1901, Gaceta, 19-VIII.

5 Gaceta, 20-VII.

6 R. D. 8-V-1903, Gaceta, 9-V.

7 Asamblea Nacional de Amigos de la Enseñanza. Sesión de Clausura. Conclusiones. Madrid, 1902, pp. 41-42.

8 Gaceta, 23-IX.

9 Ministerio de Agricultura, Industria, Comercio y Obras Públicas...: Clasificación por profesiones y provincias de las solicitudes presentadas por obreros que piden pensión para ampliar sus conocimientos en el extranjero. Madrid, 1903, 24 págs., en Archivo General de la Administración (AGA). Ministerio de Educación y Ciencia, Leg. 9929, exp. 1-2.

10 Gaceta, 8-VI.

11 Informes en AGA, Educación y Ciencia, Leg. 9929-2. 


\section{La Junta de Pensiones de Ingenieros y Obreros....}

12 R. D. de 27-V-1910, Gaceta, 28-V, del liberal Fermín Calbetón. La Junta de Patronato quedaba integrada por tres vocales natos (los presidentes del Instituto de Reformas Sociales, del Instituto Nacional de Previsión y de la Junta para Ampliación de Estudios), uno de representación de los obreros, designado por el Instituto de Reformas Sociales y cinco de libre designación del Ministro, cuatro de ellos ingenieros.

13 Gaceta, 5-IV.

14 «Consejos a los pensionados en el Extranjero», BJPIOE, I, 5, mayo, 1916, pp. 19-21.

15 WinTER, Ernesto: "Concepto de la eficacia de las Pensiones», Boletín de la Asociación de Españoles Pensionados y Expensionados en el Extranjero, (BAEPEE), II-III, 19-22, noviembre-febrero, 1925-1926, pp. 7-8.

16 Ibídem, pp. 7-8.

17 Artículos firmados por un anarquista residente en París, José Monterde, La España Nueva, 28-II-1907 y 1-III-1907. Rebatió los argumentos el Jefe de la Expedición, Enrique Sanchís, aunque de su informe se desprendía también la labor de captación ejercida sobre los pensionados por los núcleos anarquistas exilados; AGA, Ministerio de Educación y Ciencia, Leg. 9929, exp. 2.

18 Veinticinco títulos recogía el informe, pp. 48-49. Todos los datos anteriores proceden de Breve resumen de la labor realizada con las pensiones de ingenieros y obreros, memoria con paginación propia incluida al final del volumen del BJPIOE de 1920, 60 págs.

19 R. O. comunicada del Marqués de Magaz de 2-XII-1924, AGA, Ministerio de Educación y Ciencia, Leg. 9913, exp. 3. Poco después la propia Junta propondrá ampliar la medida a diversas personalidades belgas. Instancia de 15 de enero de 1925 al Subsecretario del Ministerio de Trabajo, Ibídem.

20 RR. DD. de 8-V-1920, Gaceta 9-V, y 24-V-1920, Gaceta, 25-V, y R. O. de 29-V-1920, Gaceta, 30-V.

21 Recogida en "Notas sobre la educación profesional del obrero adulto», BJPIOE, 1-3, enero-marzo, 1920, pp. 46-62.

22 R. D. de 14-V-1921, Gaceta, 22-V.

23 "Actividades de la Junta", BJPIOE, 6-7, 1920, pp. III-IX.

24 "Actividades de la Junta", BJPIOE, VI, 1-2, enero-febrero, 1921, pp. 30-32.

25 Estadísticas de comienzos de 1927, BJPIOE, XIII, 1, 2, 3, enero-febrero-marzo, 1927, pp. 4-6.

26 Ibídem, p. 6.

27 Ibídem, p. 4.

28 Boletín de la Junta Central de Perfeccionamiento Profesional Obrero, XV, 1-6, 1929, pp. 110-111.

29 Proyecto, en BJPIOE, V 11-12, noviembre-diciembre, 1920, pp. 64-65.

30 BAEPEE, II, 12-14, mayo-junio, 1925, pp. 31-33.

31 Entre otras, cartas del presidente al Directorio y al Sr. Valentín Ruiz Senén, vicepresidente de la Sociedad Hispano Americana que había obtenido la concesión de los teléfonos españoles, interesándoles por la contratación de técnicos españoles con preferencia a los extranjeros en los centros industriales del Estado o de concesión estatal, BAEPEE, I, 6, 1924, pp. 8-10.

32 "Resumen de la actuación de la Junta durante el año 1923", BJPIOE, VIII, 10, 11, 12, octubre-noviembre-diciembre, 1923, p. 103.

33 "Resumen de la actuación de la Junta durante el año 1925", BJPIOE, XI, $10,11,12$, octubre-noviembre-diciembre, 1925, p. 4. 
34 Gaceta, 5-XI.

35 R. D. L 21-XII-1928, Gaceta, 28-XII.

36 Expediente en AGA, Educación y Ciencia, Leg. 9913-3.

37 AGA, Educación y Ciencia, Leg. 9913-3.

38 A estas urgencias apelaba el Presidente del Centro en la mencionada proposición de pensiones para 1931, fecha 21 de julio. Treinta y nueve fueron los pensionados en 1927, treinta y uno en 1929, veintitrés en 1931, Ibídem.

39 Esta estéril monomanía reglamentista esta recogida en las disposiciones de 2-V-1930 (de cambio de nombre y estatuto); 19-IX-1931, Gaceta, 23-IX (transferencia al Ministerio de Instrucción Pública); 9-X-1931, Gaceta, 10-X (Comisión de Formación Profesional); 10-II-1932, Gaceta, 13-II (Dirección General de Enseñanza Profesional y Técnica); 29-II-1932, Gaceta, 5-III (Sección de Formación Profesional); 28-IX-1935, Gaceta, 29-IX (Subsecretarịa) y 24-II-1936, Gaceta, 25-II (Dirección General de Segunda Enseñanza y Enseñanza Superior).

40 DD. de 16-II-1934, Gaceta, 18-II y 13-IV-1934, Gaceta, 19-IV respectivamente. 